\title{
"Nature, green in leaf and stem". Research on plants with medicinal properties in Suriname
}

\author{
Dennis R.A. Mans* \\ Department of Pharmacology, Faculty of Medical Sciences, Anton de Kom University of Suriname, USA
}

\begin{abstract}
The widely held layman's perception of nature as a collection of animals operating against a static green background of plants is a serious misunderstanding of the complexity and dynamics of the plant biodiversity. Plants fulfill all functions that superficially only seem reserved for animals including movement, communication, and defense. For the latter purposes, plants have developed intricate and highly sophisticated chemical warning signals and defense systems to alarm friends and ward off foes. Many of these plant substances possess meaningful pharmacological properties, and some were found useful against human diseases. This paper briefly describes several aspects of plant communication and defense; gives a few examples of plant-derived therapeutics; and focuses on the potential contribution of Suriname (South America) to this scientific area.
\end{abstract}

\section{Background}

The view of the plant kingdom as a green and static background for moving animals - particularly (higher) vertebrates - is far from the reality. Paraphrasing Alfred, Lord Tennyson's (1809-1892) words "Tho' nature, red in tooth and claw" in his poem 'In Memoriam A.H.H.', the American author, physician, producer, director, and screenwriter John Michael Crichton (1942-2008) emphasizes the importance of the plant biodiversity to nature in his 1995-bestseller 'The lost world' as "Nature, green in leaf and stem". Indeed, studies from particularly the past forty years have demonstrated that plants actively participate in the complex interactions in our planet's biodiversity, displaying many functions that superficially would only be ascribed to animals including movement, communication, competition, defense, and attack.

\section{Plant movement}

Well-known examples of plants distinctively displaying movement are the flower buds from the sunflower Helianthus annuus $\mathrm{L}$. (Asteraceae) which track the sun's daily passage across the sky from east to west [1]; the shy plant Mimosa pudica L. (1753 (Fabaceae) that folds its compound leaves inward and droops them when touched [2]; the carnivorous Venus flytrap Dionaea muscipula J. Ellis (Droseraceae) (Figure 1) that captures small insects by rapidly closing its leaf ends [3]; and the roots and rhizomes of all higher and many lower plants which grow in response to gravitational pull [4], in the direction of a gradient of water concentration [5], and towards useful minerals but away from harmful substances [6].

\section{Plant communication}

Furthermore, many plants communicate with each other and their environment using an elaborate repertoire of chemical substances. Some of these substances attract insects (particularly bees, flies, wasps, butterflies, and moths) and vertebrates (mostly birds and mammals) by conferring bright colors and strong fragrances, special shapes, or nectar guides to the flowers or fruits of plants [7]. The animals facilitate fertilization by transferring pollen grains to the female reproductive organs of the plant and transport seeds away from the parent plant, enabling its propagation and the colonization of new niches, receiving valuable sources of food in return [7].

Other means of plant communication are so-called semiochemicals, plant substances involved in the transfer of information between plants and other organisms [8]. Well-studied examples are the green leaf volatiles emitted by freshly mown grass such as the mixture of aldehydes and alcohols including cis-3-hexenal [9]. These plant chemicals not only stimulate healing of the wounded site, prevent bacterial infection,

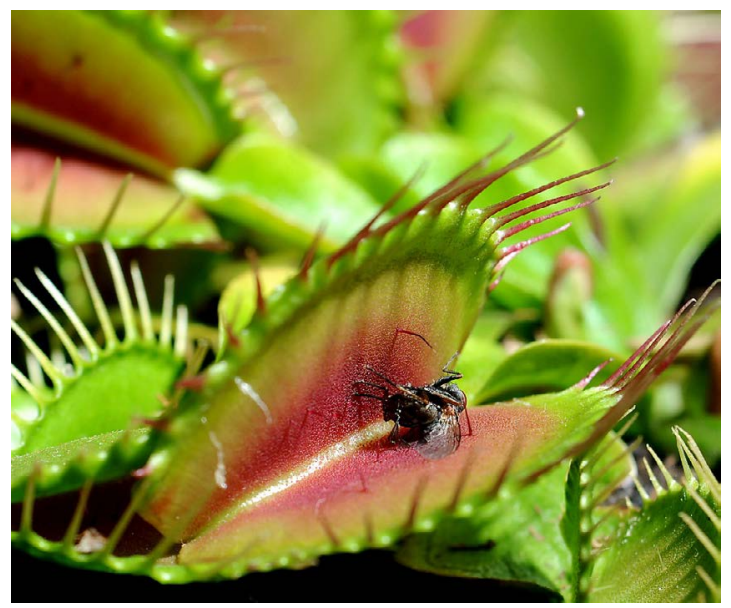

Figure 1. The Venus fly trap Dionaea muscipula J. Ellis (1768).

Correspondence to: Dennis RA Mans, Department of Pharmacology, Faculty of Medical Sciences, Anton de Kom University of Suriname, USA, Tel: 597 441071; E-mail: dennis_mans@yahoo.com

Key words: medicinal plants, plant chemicals, plant-derived therapeutics, Suriname, research lines

Received: December 10, 2016; Accepted: December 22, 2016; Published: December 26, 2016 
and inhibit fungal growth, but also represent 'distress calls' which pre-emptively stimulate the production of defensive compounds at unwounded sites, induce defense responses in neighboring plants, and/or attract 'body guard' insects which attack the perpetrators causing the injury [8]. For instance, when the wild tobacco plant Solanum mauritianum Scop. (Solanaceae) (Figure 2) is assaulted by the hornworm caterpillar Manduca sexta (Lepidoptera: Sphingidae), it emits green leaf volatiles which react with the caterpillars' saliva to produce (a) modified compound(s) that attract(s) predatory big-eyed bugs from the genus Geocoris Fallén, 1814 (Hemiptera: Geocoridae) to attack the hornworm [10].

More recently, plants have also been found to communicate with each other through an underground network of fungal mycelia which link the roots of different plants to each other [11]. The fungal networks help plants exchange nutrients and fend off competing plants by spreading toxic chemicals [11]. The networks also facilitate the spread of information about impending danger. For instance, tomato plants (Solanum lycopersicum L. (Solanaceae)) and broad beans (Vicia faba L. (Fabaceae)) under attack by fungi or aphids, have been reported to warn their neighbors about the presence of the danger, enabling them to mobilize their defenses before being harmed $[12,13]$.

\section{Plant defense}

Many plants produce, furthermore, allelochemicals which act as anti-herbivory defenses by influencing behavior, growth, or survival of herbivores [14,15]. These substances are in general secondary metabolites, i.e., organic compounds that are often produced as byproducts during the synthesis of primary metabolic products but are not directly involved in the normal growth, development, or reproduction of plants $[14,15]$. Nevertheless, they play important roles in increasing the plants' health and survival by protecting them against threats from their environment $[14,15]$. The largest groups of secondary metabolites are nitrogen-containing compounds (including alkaloids, cyanogenic glycosides, glucosinolates, and benzoxazinoids; [16]), terpenoids (including mono- and sesequiterpenoids, glycosides, and saponins; [17]), and phenolics (including flavonoids, anthocyanins, phytoalexins, and tannins; [18]). Many of these compounds act as repellents or toxins to herbivores or reduce plant digestibility [16-18].

Alkaloids render plants distasteful and generate distinctive and often detrimental changes in the (physiology of the) body of predators by targeting, among others, key metabolic enzymes, protein synthesis,

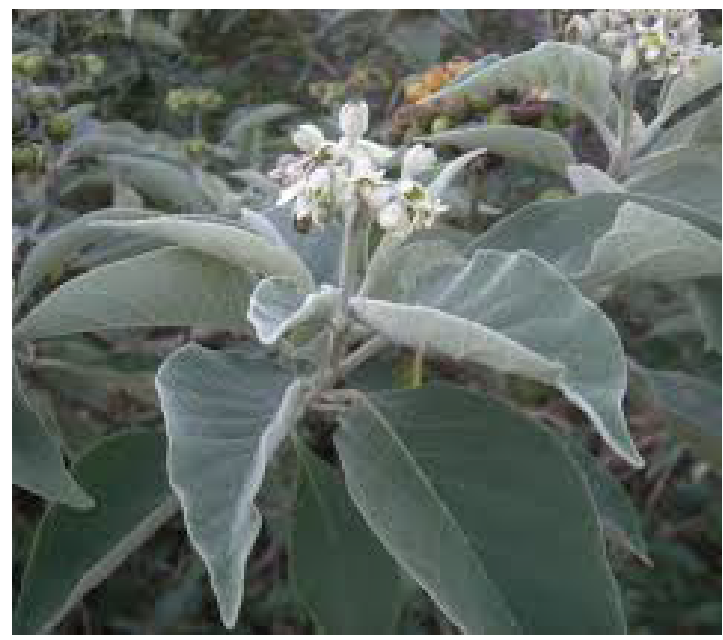

Figure 2. The wild tobacco plant Solanum mauritianum Scop. (Solanaceae).
DNA synthesis and repair, cell membrane integrity, cytoskeletal structure, and nerve transmission [16]. For instance, caffeine - the active ingredient in more than fifty plant species including the coffee plant Coffea arabica L (Rubiaceae), the tea bush Camellia sinensis L. (L.) Kuntze (Theaceae), and the cacao tree (Theobroma cacao L. (Malvaceae) - can paralyze and kill insects and fungi [19]. Nicotine from the tobacco plant Nicotiana tabacum L. (Solanaceae) is released from vacuoles in its leaves and is toxic to herbivores grazing on the leaves [20]. Many members of the plant families Fabaceae, Rosaceae, Linaceae, and Compositae synthesize cyanogenic glycosides which break down to produce hydrogen cyanide that stops cellular respiration of predators [21]. And members of the mustard family Brassicaceae synthesize glucosinolates (also known as mustard oil glycosides), sulfur-containing compounds that produce cyanide gas when broken down by enzymes [22].

Monoterpenoids and sesquiterpenoids are the primary components of essential oils, the highly volatile compounds that contribute to the fragrance of plants that produce them [17]. Although many spices, seasonings, condiments, and perfumes contain essential oils [17], these plant chemicals function biologically as toxins against fungal or bacterial attack [17]. A few examples are peppermint and spearmint from Mentha spp., rosemary from Rosmarinus spp., cinnamon from Cinnamomum spp., and bay leaf from Laurus spp. [17]. And certain monoterpenoid esters such as pyrethrins produced by chrysanthemum plants (family Asteraceae) act as insect neurotoxins and served as the blue print for commercially available synthetic insecticides such as the pyrethroids permethrin and cypermethrin [23]. Examples of insect-repelling triterpenoids are the limonoids in lemon and orange peels [24], azadirachtin in the neem tree Azadirachta indica A. Juss., 1830 (Meliaceae) (Figure 3) [25], and citronella in the lemon grass Cymbopogon citratus Stapf. (Gramineae) [26]. Other triterpenoids such as the cardiac glycosides in the foxglove Digitalis purpura L. (Scrophulariaceae) and in species of the milkweed Asclepias are highly toxic to vertebrate herbivores including humans, and can cause heart attacks if ingested in high quantities [27]. Finally, glycosylated triterpenoids called saponins are present in the cell membranes of many plant species and have amphiphilic properties enabling them to disrupt the cell membranes of invading fungal pathogens and lyze red blood cells of herbivores [28].

Flavonoids help provide color, fragrance, and taste to fruits, flowers and seeds, which make them attractive for insects, birds, or mammals which aid in pollen or seed transmission [18]. These compounds also protect plants against insect pests by influencing their growth and

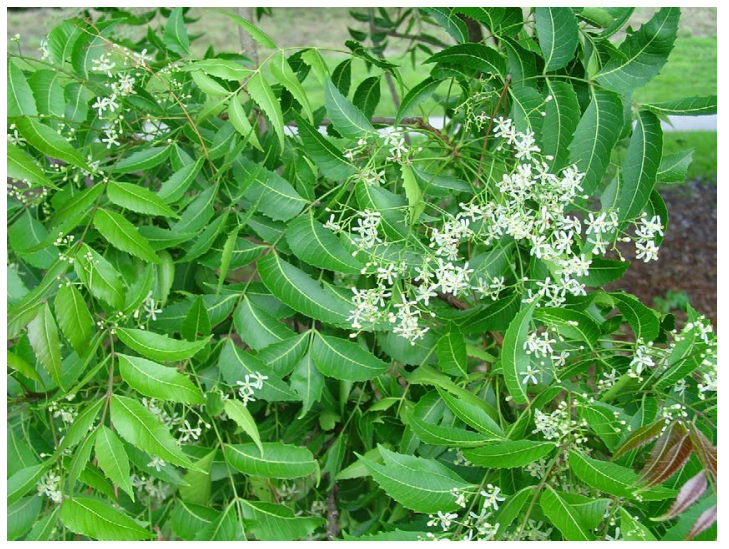

Figure 3. The neem tree Azadirachta indica A. Juss. 
development [29,30]. Quercetin-3-O-rutinoside, for instance, prevents certain insects from laying eggs [31]. Anthocyanins are flavonoid pigments that are responsible for the colors of many flowers and fruits of plants as well as the leaves of deciduous plants in fall, and protect foliage from the damaging effects of ultraviolet radiation [32]. Phytoalexins are isoflavonoids which are produced in response to pathogen attack and disrupt the metabolism or cellular structure of micro-organisms [33]. A well-studied example of this group of plant chemicals is rishitin produced by tomatoes and potatoes (family Solanaceae) [34]. Tannins are water-soluble flavonoid polymers that inhibit herbivore digestion by binding to consumed plant proteins, making them more difficult for animals to digest, and by interfering with protein absorption and digestive enzymes [35].

\section{Plant chemicals as therapeutics}

When considering the meaningful pharmacological properties of many plant chemicals, it is understandable that several of them are useful as therapeutics. Not surprisingly, humans have since long appreciated the significance of plant-derived substances as therapeutics. This can be derived from archeological finds [36] and the pharmacopeia from the ancient Chinese (2,800 BC), Egyptians (1,550 BC), Assyrians ( $7^{\text {th }}$ century BC), and Greeks ( $4^{\text {th }}$ century BC and 75 BC) [36]. In fact, until the $19^{\text {th }}$ century $\mathrm{AD}$, medicinal plants were by far the most widely used (and often the only available) treatment modality for human diseases [36].

From the early 1800s on - with the isolation of morphine from the opium poppy Papaversomniferum L. (Papaveraceae) [37] - a large variety of pharmacologically active substances has been identified in plants. Many of these compounds turned out clinically useful. A few examples are the muscle relaxant d-tubocurarine from Strychnos guianensis (J.B. Aublet) Martius, 1843 and Strychnos toxifera L. (Loganiaceae) [38]; the pupil dilator atropine from the deadly nightshade Atropa belladonna L. (Solanaceae) [39]; the cardiac glycoside digoxin from the foxglove D. purpura [40]; the anti-malarial quinine from the quina plant Cinchona officinalis L. (Rubiaceae) [41]; the antipyretic quassine from the bitterwood Quassia amara L. (Simaroubaceae) (Figure 4) [42]; the antineoplastic agent vincristine from the Madagascan periwinkle Catharanthus roseus (L.) G.Don, 1837 (Apocynaceae) [43]; and the hypoglycemic agent metformin from the French lilac Galega officinalis L. (Fabaceae) [44].

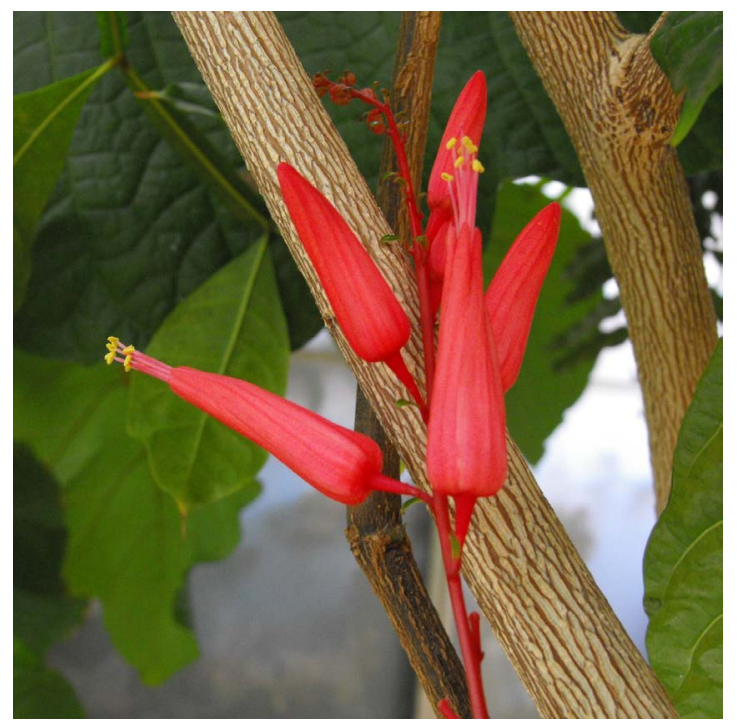

Figure 4. The bitterwood Quassia amara L. (Simaroubaceae)
It is generally believed that these and many other substances only represent a relative handful of the bewildering chemical diversity that lies awaiting in the green pharmacies throughout the world, particularly in the astonishingly biodiverse tropical rain forests [45]. It is even anticipated that exploitation of this virtually inexhaustible chemical storehouse may produce medicines for treating major global health threats including cardiovascular ailments, cancer, diabetes mellitus, and degenerative brain disorders such as Alzheimer's disease. This may also hold true for the biodiversity of the Republic of Suriname.

\section{Background on Suriname}

\section{Geography, economy, and people}

The Republic of Suriname is located on the north-east coast of South America and borders the Atlantic Ocean to the north, French Guiana to the east, Brazil to the south, and Guyana to the west (Figure 5). The country's land area of $165,000 \mathrm{~km}^{2}$ can be distinguished into a northern narrow low-land coastal area that harbors the capital city Paramaribo as well as other urbanized areas, a broad but sparsely inhabited savannah belt, and a southern forested area that comprises about three-quarters of its surface area and largely consists of dense, pristine, and highly biodiverse tropical rain forest. Roughly $80 \%$ of the population of about 570,000 lives in the urbanized northern coastal zone while the remaining $20 \%$ populates the rural and interior savannas and hinterlands.

Situated on the Guiana Shield - a Precambrian geological formation estimated to be 1.7 billion years old - Suriname is one of the regions with the largest expanse of undisturbed tropical rain forest in the world, harboring a very high biodiversity that includes many endemic animal and plant species [46]. The high mineral density contributes, furthermore, to Suriname's ranking as the seventeenth richest country in the world in terms of natural resources and development potential [47]. Suriname's most important economic means of support are crude oil drilling, bauxite and gold mining, agriculture, fisheries, forestry, as well as ecotourism [48]. These activities contributed substantially to the gross domestic income in 2014 of USD 5.21 billion and an average percapita income in that year of USD 9,325 [48]. This positions Suriname on the World Bank's list of upper-middle income economies [48].

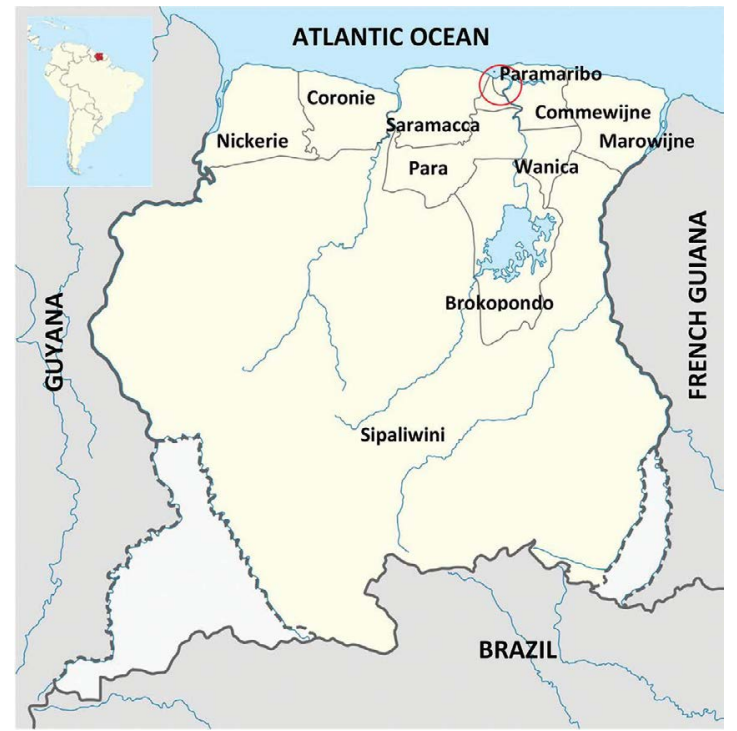

Figure 5. Map of Suriname. The insert indicates the location of Suriname in South America. 
Suriname's population is among the most ethnically diverse in the world, comprising the indigenous Amerindians; descendants from enslaved Africans brought in between the $16^{\text {th }}$ and the $19^{\text {th }}$ century; descendants from contract workers from China, India, and Indonesia who arrived in the second half of the $19^{\text {th }}$ century and the first half of the $20^{\text {th }}$ century; descendants from a number of European countries; and more recently, immigrants from various Latin American and Caribbean counties including Brazil, Guyana, French Guiana, Haiti, etc. [50]. All these ethnic groups have largely preserved their own specific identity, making Suriname one of the culturally most diverse countries in the world [51]. This also holds true for the country's ethnopharmacological practices [51].

\section{Health infrastructure}

The availability, accessibility and affordability of health care in Suriname is the responsibility of the Ministry of Health, which is led by the Minister of Health and the Director of Health (the Chief Medical Officer). The total health expenditure in 2014 was $5.7 \%$ of the GDP, and the per capita health expenditure in that year was USD 589 [49]. The main responsibilities of the ministry are the planning, coordination, inspection, and monitoring and evaluation of, as well as policy development and setting standards to the country's health system. These activities are in detail described in reference [52].

The health costs for the economically weakest individuals are covered by the Ministry of Social Affairs. Government employees and employees of government-related companies are mandatory insured at the State Health Foundation. Essential pharmaceuticals are imported, stocked, and distributed by the National Pharmaceutical Import and Distribution Company. These medicines are identified by the Board for Essential Pharmaceuticals that consist of various players in the field of pharmacy and pharmacology in Suriname.

Public health affairs are allocated to the Bureau of Public Health and the Inspectorate. These institutions are in charge of, among others, vaccination programs, maternal and child health care, and the development of programs to combat parasitic and microbial diseases such as malaria, leishmaniasis, chikungunya, and zika. Primary health care in Suriname's coastal area and hinterlands is provided by the government-subsidized Regional Health Service and Medical Mission, respectively, in addition to a number of private practitioners. Other governmental primary health care facilities are the Youth Dental Foundation that provides dental care for schoolchildren, and the Dermatology Clinic that provides services for dermatological diseases, sexually transmitted diseases, and HIV/AIDS. Suriname's Ministry of Health further supports the Kidney Dialyses Center and the Blood Bank, and recognizes various non-governmental organizations which provide specific health care services such as the Lobi Foundation specialized in sexual reproductive health, family planning, and screening for cervical cancer and HIV/AIDS. Secondary care and specialist care are provided by two private and two government-supported hospitals in Paramaribo and one public hospital in the western district of Nickerie. The combined capacity of the hospitals in Paramaribo is about 1,200 beds. The Academic Hospital Paramaribo also functions as training facility for both general practitioners and medical specialists, provides twenty-four-hour emergency medical care, and has recently put into action a Radiotherapeutic Center. There is, furthermore, a psychiatric hospital in Paramaribo that has a capacity of 280 beds.

Patients who need specialized therapy that is not available in Suriname (particularly those suffering from certain malignancies) are sent abroad - to the Netherlands or Colombia - for treatment.
All expenses are covered by the Ministry of Health that has reserved a special budget for these cases. The previous arrangement with The Netherlands for cardiac surgery missions to Suriname has resulted in the built-up of sufficient capacity to perform most of these procedures by the cardiologists of the Academic Hospital Paramaribo. Similarly, patients with poor eye sight due to cataract who were initially operated in Cuba, are now treated in Suriname by specialists from the Suriname Eye Center [53].

\section{Use of traditional medicines}

Despite the broad availability of modern health care, the use of traditional medicines is deeply rooted in all ethnic groups in Suriname. This is probably for an important part attributable to the fact that all these groups have preserved much of their original ethnopharmacological practices. For instance, the centuries-old medicinal traditions of the indigenous Amerindians involve the use of more than 300 plant species for treating approximately 75 distinct disease conditions and are still very much alive [54]. Importantly, many Amerindian disease descriptions closely correspond those in Western allopathic medicine, and the treatments are often successful [54]. An example is the indigenous use of the dried leaves of the bitter gourd Momordica charantia L. (Cucurbitacea) (Figure 6) for treating the symptoms of diabetes mellitus, which is supported by the hypoglycemic effects of $M$. charantia preparations in various animal models [55].

As well, several traditional medicinal practices of Afro Surinamese can be directly traced back to the ancient African belief that both physiological and psychological conditions result from an imbalance between 'hot' and 'cold' and can be reversed by removing the 'cold' [56]. Accordingly, Surinamese Creoles and Maroons frequently treat obstructions in gastrointestinal tract, airways, blood circulation, genitourinary system, or mental state (interpreted as 'colds' or 'kowrus') using a variety of plant-based kowru dresis ('medicines against a cold') $[57,58]$.

And the adherence of many Surinamese Chinese, Hindustanis, and Javanese to the use of the rhizomes from the milkvetch or huáng qi Astragalus propinquus Schischkin (Fabaceae) to strengthen the vital energy Qi for general health and well-being and for boosting immunity $[59,60]$; the leaves from the neem plant $A$. indica for treating a variety of ailments including colds, fevers, high blood pressure, diabetes mellitus], and chicken pox [61,62]; and the rhizomes from the laos Alpinia galanga (L.) Willd. (Zingiberaceae) for treating the fungal skin infection 'lota' (pityriasis alba), stomach cramps, and dysentery [63], respectively, find their origin in traditional Chinese medicine, Indian

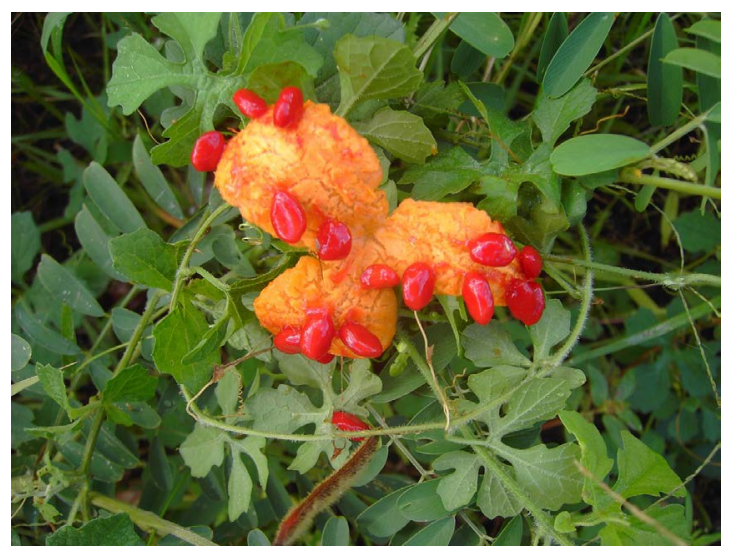

Figure 6. The bitter melon Momorica charantia L. (Cucurbitaceae). 
Ayurveda, and Indonesian Jamu, respectively.

However, in many cases there is no or only marginal scientific evidence to support these claims of therapeutic efficacy. For this reason, it was decided to implement a broad and large-scale program of collection and testing of Surinamese plants with presumed medicinal properties. This effort is led by the academic chair of Pharmacognosy at the Department of Pharmacology, Faculty of Medical Sciences, Anton de Kom University of Suriname. Other important players in the program are the Department of Physiology of the Faculty of Medical Sciences; the Department of Organic Chemistry of the Faculty of Mathematics and Earth Sciences; the National Herbarium Suriname; as well as a number of scientific research institutions abroad. The program receives financial support from the Suriname Conservation Foundation, an environmental organization that is deeply committed to the sustainable development of Suriname's biodiversity. Hereunder follows a detailed account of some of the research activities on medicinal plants in Suriname.

\section{Research on medical plants in Suriname}

\section{Plant selection}

The candidate plants for our studies are mainly selected on the basis of generally available ethnopharmacological information that is not protected by intellectual property rights. In conformity with the conditions stipulated by the Nagoya Protocol on Access and Benefit Sharing [64], no ethnobotanical data are gathered by consulting or interviewing holders of such information. This agreement has been reached in 2010 in Nagoya, Japan, as a supplementary agreement to the 1992-Convention on Biological Diversity from Rio de Janeiro, Brazil [65], and protects, among others, the traditional knowledge associated with genetic resources while addressing the necessity of fair and equitable sharing of the benefits arising from its utilization [65]. Importantly, no plants are selected that occur on the IUCN Red List of threatened species [66].

The required information is accumulated from amply available oral and written sources on the popular medicinal use of plants in Suriname. Indeed, the country's unique mixture of cultures provides a wealth of anecdotal information on the folkloristic treatment of diseases, a number of written accounts [67-72], academic theses [63,73-75], and reference works $[58,76]$.

These sources report, for instance, on the generally acknowledged Amerindian use of the dried leaves from the bitter melon M. charantia against the symptoms of diabetes mellitus [55]; the Afro-Surinamese use of Q. amara for treating malaria fever [77]; the Hindustani use of the leaves from the neem plant $A$. indica to boost the immune system [62]; and the Javanese use of the leaves from the cat's whiskers Orthosiphon aristatus (Blume) Miq. (Lamiaceae) for treating kidney stones and renal colics [78]. They often also provide information about the plant part(s) to use, the mode of preparation, and the schedule of administration preparation. For instance, Q. amara tonics are ingested on a daily basis, and often prepared by filling a 'bitter cup' carved out of the plant's hardwood with water (or rum), leaving it undisturbed overnight, and drinking the liquid the next morning [77]. And the series of plants we recently evaluated for their potential antileishmanial efficacy [79] had largely been selected on the basis of a previously published comprehensive survey on ethnopharmacological remedies for treating this condition [80].
The ethnopharmacological information is often combined with data from the scientific literature. The latter data may provide (chemosystemic) information on related plant species or genera to include in the tests, as well as clues about the chemical nature and mechanism of action of the pharmacologically active ingredient(s). Thus, literature data localizing the antimalarial ingredients of $Q$. amara (among others, simalikalactone D, simalikalactone E, quassin, and neoquassin; [81]) to the plant's bark and leaves, support the use of extracts of these plant parts in studies with this plant.

\section{Plant collection}

When certain plants have been selected for collection as mentioned above, the botanists of the National Herbarium of Suriname (BBS) are consulted in order to ascertain where and when the desired plant species, genera, or families can be encountered in Suriname. Then, for each species, the locations where that species is likely to be found and the ideal season for collection are determined, and particular areas are designated for collection. Importantly, these areas must be free from herbicidal or pesticidal use for at least the preceding six months.

Before organizing expeditions, a collection permit must be obtained from the Surinamese Ministry of Physical Planning, Land- and Forestry Management. This is to obtain guidelines for responsible expeditions, limiting the number of collections per area and preventing excessive collection of rare species. As mentioned before, the collected plants must not be on the International Union for Conservation of Nature's Red List of endangered or threatened species [66]. Furthermore, a particular location can be visited only twice per year, protected species cannot be collected, no trees can be felled, samples of bark must be taken from only one side so as not to gird the tree, and root samples can only be taken from the periphery.

If possible, several parts of a plant are collected (leaves, twigs, bark, flowers, fruits, and/or roots), which are separately cataloged. In general, 50 to 100 grams of a sample must remain after drying in order to allow for the preparation of sufficient extract to carry out initial laboratory studies. Depending on the succulence, this may require the collection of as much as $2 \mathrm{~kg}$ of leaves or 500 grams of roots and twigs.

Samples are labeled in the field and returned to the base camp, weighed, taxonomically characterized, placed in boxes, and shipped to our extraction laboratory. The shipments are accompanied by the complete taxonomy of the species collected; notes on the plant parts collected as well as the location and date of collection; the rationale for collection, etc. If necessary, voucher specimens are prepared and deposited at the Herbarium for future reference.

\section{Plant extraction}

The collected plant parts are thoroughly washed with distilled water, dried in open air if indicated, washed again, and subsequently processed on the basis of the ethnopharmacological method of preparation. Thus, if a decoction is prepared from the dried leaves of a certain plant, than the leaves of that plant are collected, air-dried, and extracted in boiling water for our experiments. Thus, samples of $Q$. amara and $A$. indica are prepared for our studies by soaking samples of macerated hardwood or air-dried leaves, respectively, in distilled water or ethanol for at least eight hours and at room temperature [62,77].

The plant extracts are filtered, concentrated by freeze-drying or rotavap evaporation so as to obtain a stable powder, divided in aliquots of $2 \mathrm{~g}$, labeled, and stored at $-80{ }^{\circ} \mathrm{C}$ until testing. For experiments, the required amounts of extracts are rapidly thawed, liquefied in ultra-pure 
water (in the case of aqueous extracts) or cell culture-grade DMSO or ethanol (in the case of organic extracts), and further dissolved to the desired concentrations by shaking for $1 \mathrm{~h}$ at $50^{\circ} \mathrm{C}$. The suspensions are then centrifuged for $5 \mathrm{~min}$ at $3000 \mathrm{rpm}$ after which the supernatants are collected, sterilized through $0.22 \mu \mathrm{M}$ filters (Millipore), and tested.

\section{Preclinical evaluation}

Thus far, approximately 500 extracts have been prepared from about 200 different plant species which are in various stages of preclinical evaluation. Until now, the program has primarily focused on plants with a presumed efficacy against cardiovascular, neoplastic, and respiratory conditions, as well as cutaneous leishmaniasis. More recently, with the realization of the importance of angiogenesis to the pathophysiology of many diseases, emphasis is also being placed on plants with angiogenesis-interfering properties. Some of our research activities are addressed hereunder.

\section{Medicinal plants against hypertension}

Plant extracts with presumed efficacy against arterial hypertension were evaluated for such an activity using isolated guinea pig atria [82]. Thus, the heart from a guinea pig was quickly dissected and the atria were isolated. The isolated atria were transferred to an organ bath containing $40 \mathrm{~mL}$ of Ringer-Locke solution kept at $30^{\circ} \mathrm{C}$ and gassed with pure oxygen, and the tip of one atrium was attached to a fixed point in the bath and that of the other to a force transducer.

The isolated guinea pig atria were exposed to a plant extract, an agonist such as norepinephrine, and/or an antagonist such as atenolol, either alone or at certain combinations. The resulting forces of contraction were registered by the force transducer and monitored with a desktop computer through a bio-amplifier connected to an analog-digital converter. Signals were recorded with the Chart for Windows 4.2.3 software. The relative contractility and beating frequency caused by one of the test substances were derived from the average peak values of their respective recordings, and were expressed with respect to average values registered in the presence of buffer alone. The counteracting effects of the antagonist on the actions of the agonist were taken to validate the usefulness of the model to carry out the evaluations.

Using this assay, ten popularly used aqueous plant extracts were evaluated for their potential efficacy against hypertension [82]. The extracts from the bilimbi Averrhoa bilimbi L. (Oxalidaceae) (Figure 7), the black catnip Phyllanthus amarus Schum. \& Thonn. (Euphorbiaceae), and the eggplant Solanum melongena L. (Solanaceae) were found to decrease the contractility of norepinephrine-stimulated atria by 50 to $100 \%$ while not affecting the beating frequency. These observations suggest that the apparent blood pressure-lowering effects of these preparations may be related to a reduction in cardiac output, and provide support for their popular use against hypertension.

\section{Medicinal plants against spasms}

Plant preparations that are used for relieving spasms were evaluated for such properties using isolated guinea pig ilei [83]. After the ileum was removed, it was cleaned and left to stabilize overnight in Tyrode buffer at $4{ }^{\circ} \mathrm{C}$. The next day, a piece of ileum of about $2-\mathrm{cm}$ length was placed in an organ bath containing $40 \mathrm{~mL}$ of Tyrode buffer that was kept at $37^{\circ} \mathrm{C}$ and mixed with $5 \% \mathrm{CO}_{2}$ in air.

The ileum was exposed to a plant extract, an agonist such as acetylcholine or histamine, and/or an antagonist such as atropine

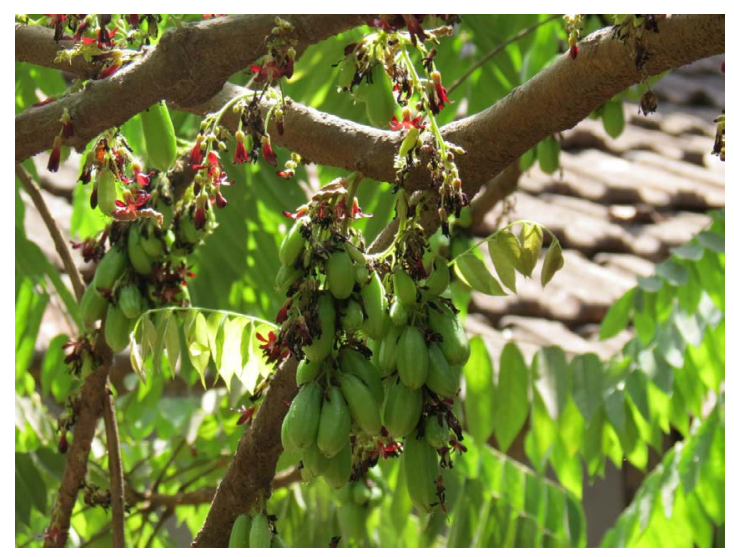

Figure 7. The bilimbi Averrhoa bilimbi L. (Oxalidaceae).

or chlorpheniramine, either alone or at certain combinations. The resulting forces of smooth muscle contraction were detected by a sensor connected to the ileum, processed by a bio-amplifier and an analogdigital converter, and monitored using the above-mentioned software. Potential spasmolytic properties of a plant extract were derived from its capacity to reduce forces of smooth muscle contraction of the ileum induced by an agonist after correction for basal tone (readings in the presence of Tyrode buffer alone). Again, the counteracting effects of the antagonists were taken to validate the usefulness of the ileum preparation to carry out the evaluations.

Using this model, aqueous extracts from (parts of) plants that are popularly used as spasmolytics were evaluated for such an activity [83]. The results from this study suggested that preparations from $C$. citratus (Figure 8), the mother of thousands Kalanchoë pinnata (Lam.) Pers. (Crassulaceae), the bird of paradise Caesalpinia pulcherrima (L.) Schwartz (Caesalpiniaceae), and the annatto Bixa orellana L. (Bixaceae) may indeed possess properties and relieve spasms. On the other hand, those from the sea island cotton Gossypium barbadense L. (Malvaceae) and the African marigold Tagetes erecta L. (Compositae) may exacerbate these conditions.

\section{Medicinal plants against airway constriction}

Plant-derived preparations with a potential bronchospasmolytic effect were evaluated using a chain prepared from isolated guinea pig tracheal rings [84]. Thus, the trachea from the anaesthetized animals was quickly removed, cut transversally between the cartilage segments so as to obtain a number of rings of tracheal smooth muscle. Eight rings were tied together with cotton to form a chain which was placed in an organ bath containing Tyrode buffer kept at $37^{\circ} \mathrm{C}$ and mixed with a constant flow of ambient air. One end of the tracheal chain was attached to a fixed point in the organ bath and the other to a force transducer.

The chain was exposed to a plant extract, an agonist such as acetylcholine or histamine, and/or an antagonist such as atropine or chlorpheniramine, either alone or at certain combinations. The forces of smooth muscle contraction were processed and monitored as mentioned above. Forces of smooth muscle contraction were corrected for basal muscle tone (readings in the presence of Tyrode buffer alone) and expressed relatively to those found with an agonist alone. Once again, the actions of the antagonists served as positive controls.

This model was used to verify the claim of efficacy of plants that are popularly used to relieve respiratory distress [84]. Our results 


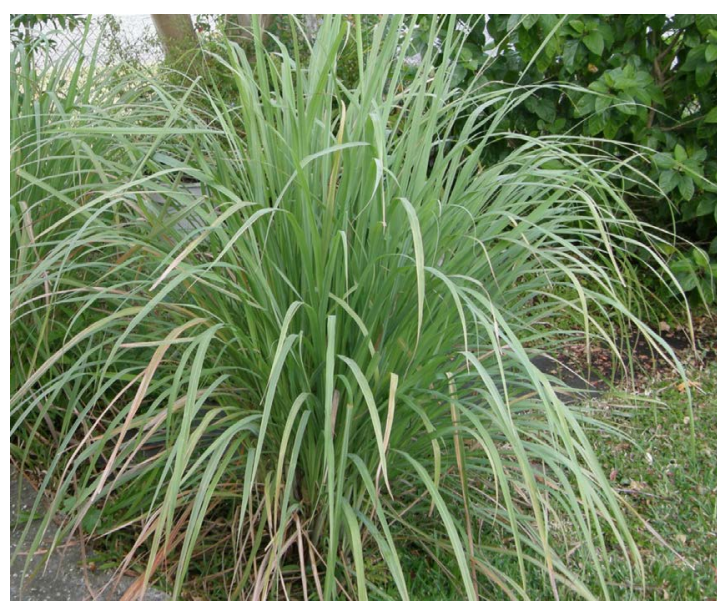

Figure 8. The lemon grass Cymbopogon citratus Stapf. (Gramineae).

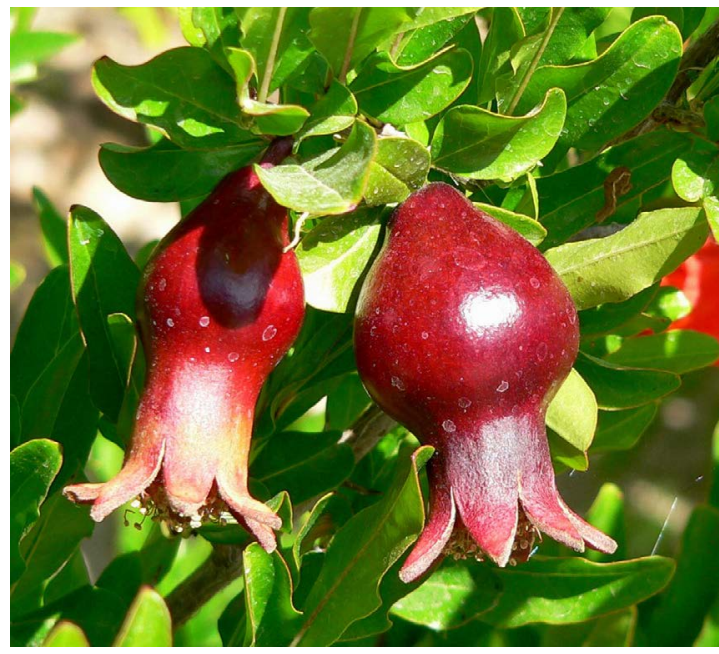

Figure 9. The pomegranate Punica granatum L. (Punicaceae).

suggested that aqueous extracts from $K$. pinnata, the pomegranate Punica granatum L. (Punicaceae) (Figure 9), the spiny amaranth Amaranthus spinosus L. (Amaranthaceae), the tropical milkweed Asclepias curassavica L. (Asclepiadaceae), and B. orellana may elicit bronchospasmolytic effects through antagonism of the muscarinic and/ or $\mathrm{H}_{1}$ histamininergic receptor. These findings support the popular use of these plants against bronchoconstriction.

\section{Medicinal plants against leishmaniasis}

Plant extracts with a presumed efficacy against the parasitic disease (cutaneous) leishmaniasis are submitted to a promastigote assay [85] as well as an amastigote assay [86].

In the promastigote assay [85], promastigotes of various Leishmania species and THP-1 monocytic cells are seeded in 96-well flat-bottomed microplates and exposed for $72 \mathrm{~h}$ to serial dilutions of the plant extracts. Amphotericin is used as a reference compound, and untreated parasites or THP-1 cells in medium only serve as controls. At the end of the incubations, numbers of surviving parasites and monocytes are determined by staining with Alamar Blue ${ }^{\text {. }}$. The effect of a plant extract on the promastigotes and monocytes is expressed as $\mathrm{IC}_{50}$ value, i.e., the concentration of the extract that leads to $50 \%$ inhibition of their growth when compared to untreated controls.
In the amastigote assay [86], THP-1 monocytic cells are inoculated in 96-well flat bottomed microplates and stimulated for $48 \mathrm{~h}$ with phorbol 12-myristate 13-acetate to obtain differentiated, non-dividing macrophage-like cells. Next, the THP-1 cells are subjected to infection by Leishmania (Leishmania) donovani promastigotes at a ratio of 10 parasite per THP-1 cell. Sixteen hours later, the infected THP-1 cells are exposed for $96 \mathrm{~h}$ to serial dilutions of the plant extracts or to medium only (untreated control). Uninfected THP-1 cells with no exposure to plant extracts serve as a blank, and the anti-leishmanial drug amphotericin B is used as a reference compound. At the end of the incubations, the number of viable amastigotes is assessed using a quantitative Leishmania-specific colorimetric assay based on the enzymatic reduction of Leishmania-native disulfide trypanothione. The effect of a plant extract on the (intracellular) amastigotes is expressed as $\mathrm{IC}_{50}$ value, i.e., the concentration of the extract that leads to $50 \%$ inhibition of their growth when compared to untreated controls.

In Suriname, cutaneous leishmaniasis is so far the principal form of leishmaniasis and it is mainly caused by Leishmania (Viannia) guyanensis $[87,88]$. Pentamidine isethionate given intramuscularly at the dose of three injections of $4 \mathrm{mg} / \mathrm{kg}$ on days 1,4 , and 7 is the first-line drug and the only treatment option for cutaneous leishmaniasis caused by L. (V.) guyanensis in Suriname [89]. However, many patients with cutaneous leishmaniasis in Suriname's interior cannot afford the costs of treatment and transportation to health centers in Paramaribo, and instead use traditional herbal substances [80]. However, the scientific evidence to support the therapeutic usefulness of these substances is scant. If efficacious, some of them may represent lead compounds for the development of novel drugs for treating cutaneous leishmaniasis.

Thus, parts from twenty-five plants that are used in Suriname against cutaneous leishmaniasis were evaluated for their effect on the viability of $L$. (V.) guyanensis AMC, $L$. (L.) major NADIM5, and $L$. (L.) donovani GEDII promastigotes as well as intracellular amastigotes of $L$. (L.) donovani BHU814 in infected THP-1 macrophage-like cells [79]. Selectivity was assessed by cytotoxicity against the THP-1 cells. The only plant extract that showed potentially meaningful anti-leishmanial activity was that from the wolfapple Solanum lycocarpum A.St.-Hil. (Solanaceae) (Figure 10) that displayed mean $\mathrm{IC}_{50}$ values of $<16$ to 51 $\mu \mathrm{g} / \mathrm{mL}$ against the promastigotes, $374 \mu \mathrm{g} / \mathrm{mL}$ against the amastigotes; and $>500 \mu \mathrm{g} / \mathrm{mL}$ against the THP-1 cells [79]. Thus, S. lycocarpum preparations may be useful for treating cutaneous leishmaniasis and may cause relatively low toxicity to the normal tissues, validating their ethnopharmacological use against this disease. In light of the lack of efficacious forms of treatment of cutaneous leishmaniasis, this plant extract may also represent an interesting candidate for new drug

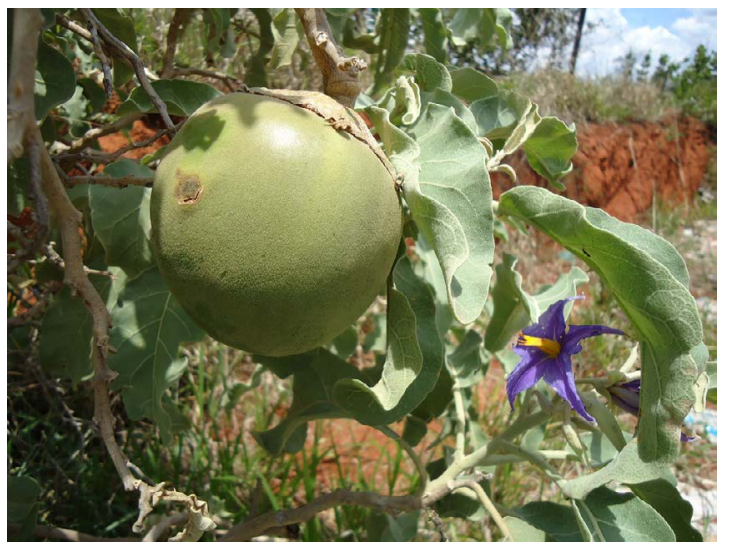

Figure 10. The wolfapple Solanum lycocarpum A.St.-Hil. (Solanaceae). 
development programs.

\section{Medicinal plants with angiogenesis-interfering properties}

Research efforts spanning more than four decades have revealed that defects in angiogenesis - the formation of either excessive or insufficient blood vessels - is at the basis of more than seventy distinct diseases that affect hundreds of millions of individuals worldwide [90,91]. Despite the availability of a broad arsenal of therapeutic anti-angiogenic or angiogenesis-stimulating therapies for correcting (the consequences of) faulty angiogenesis [92], there is a need of more efficacious and less toxic angiogenesis-interfering forms of treatment. For this reason, our research efforts are also directed towards Surinamese plants with potential anti- or pro-angiogenic properties.

As angiogenesis involves, among others, the proliferation and migration of endothelial cells, as well as their rearrangement to form capillary-like structures [90,93], the plant extracts are evaluated for their effects on the proliferation and motility of cultured human umbilical vein endothelial cells (HUVECs) using a sulforhodamine B cell proliferation assay [94], a migration assay using modified Boyden chambers [95], a scratch-wound healing assay [96], as well as a tube formation assay [97], respectively. In parallel, the plant extracts are assessed for their capacity to interfere with the regeneration of the amputated caudal tail fin of the zebrafish Danio rerio, and their capability to affect total sub-intestinal vessel length of embryos of the $\operatorname{Tg}($ flila:EGFP)yl/+ variant of these fish $[98,99]$.

Using these models, an aqueous extract from the wild sage Lantana camara L. (Verbenaceae) (Figure 11) was found to delay the regrowth of the amputated fin and the formation of sub-intestinal vessels in zebra fish by about 30 and 50\%, respectively, and to inhibit HUVEC scratch-wound closure and capillary-like structure formation by almost 100 and 50\%, respectively [100]. These results suggest that the $L$. camara extract possesses marked anti-angiogenic properties, making it a candidate for evaluation in diseases caused by excessive angiogenesis.

\section{Future prospects}

Suriname's rich cultural diversity fuels comprehensive ethnobotanical traditions [57,63,67-75] while its unique plant biodiversity provides ample raw material to be processed into ethnopharmacological preparations for treating a multitude of disease conditions $[58,76]$. Unfortunately, the scientific evidence to support the therapeutic usefulness of these substances is in many cases insufficient.

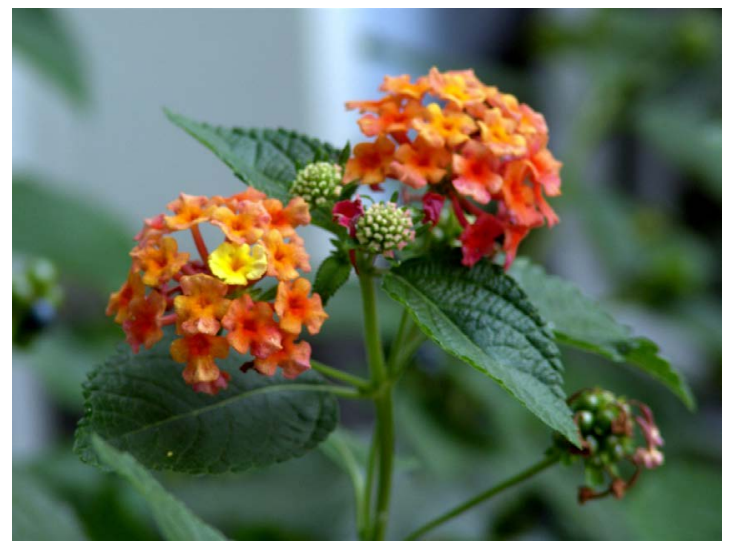

Figure 11. The wild sage Lantana camara L. (Verbenaceae).
However, if efficacious, some of them may represent lead compounds for the development of novel therapeutics.

This is one of the principal reasons for implementing the current research program on the collection and testing of Surinamese plants with presumed medicinal properties. The program has already yielded some successes, a few of which have been described above. The challenge now is, to translate these achievements from the bench to applications for the bedside.

For this purpose, the crude plant extracts that prove active in our initial tests will be subjected to bioassay-guided purification in order to obtain the pharmacologically active ingredient(s). The purified compounds will be further characterized in terms of their chemical structure, and molecular studies will be carried out in order to assess them for their mechanism of action. These studies are now in preparation. Hopefully, these efforts will foster the ultimate goal of the program, the development of efficacious novel therapeutics.

\section{References}

1. Lang ARG, Begg JE (1979) Movements of Helianthus annuus leaves and heads. J Appl Ecol 16: 299-305.

2. Vanden Driessche T (2000) Nutations in shoots and in desmodium lateral leaflets, nyctinastism and seismonastism in Mimosa pudica. Comparison and evolution of morphology and mechanism. Biol Rhythm Res 31: 451-468.

3. Forterre Y, Skotheim JM, Dumais J, Mahadevan L (2005) How the Venus flytrap snaps. Nature 433: 421-425. [crossref]

4. Perrin RM, Young LS, Murthy U M N, Harrison BR, Wang Y, et al. (2005) Gravity signal transduction in primary roots. Ann Bot 96: 737-743.[crossref]

5. Eapen D, Barroso ML, Ponce G, Campos ME, Cassab GI (2005) Hydrotropism: roo growth responses to water. Trends Plant Sci 10: 44-50.[crossref]

6. Filippenko VN (2001) Evidence for the active and passive chemotropisms in roots. Russian J Plant Physiol48: 431-437.

7. Howe HF, Smallwood J (1982) Ecology of seed dispersal. Annu Rev Ecol System 13 201-228.

8. Witzany G (2006) Plant communication from biosemiotic perspective: differences in abiotic and biotic signal perception determine content arrangement of response behavior. Context determines meaning of meta-, inter- and intraorganismic plant signaling. Plant Signal Behav 1: 169-178.[crossref]

9. Hatanaka A, Kujiwara T, Matsui K (1995) The biogeneration of green odour by green leaves and its physiological functions - past, present and future. Z Naturforsch50: 467472 .

10. Scala A, Allmann S, Mirabella R, Haring MA, Schuurink RC (2013) Green leaf volatiles: a plant's multifunctional weapon against herbivores and pathogens. Int J Mol Sci 14: 17781-17811.[crossref]

11. Gorzelak MA, Asay AK, Pickles BJ, Simard SW (2015) Inter-plant communication through mycorrhizal networks mediates complex adaptive behaviour in plant communities. AoB PLANTS7: plv050.

12. Song YY, Zeng RS, Xu JF, Li J, Shen X, et al. (2010) Interplant communication of tomato plants through underground common mycorrhizal networks. PLoS One 5: e13324.[crossref]

13. Babikova Z, Gilbert L, Bruce TJ, Birkett M, Caulfield JC, et al. (2013) Underground signals carried through common mycelial networks warn neighbouring plants of aphid attack. Ecol Lett 16: 835-843.[crossref]

14. Mithöfer A, Boland W (2012) Plant defense against herbivores: chemical aspects. Annu Rev Plant Biol 63: 431-450.[crossref]

15. War AR, Paulraj MG, Ahmad T, Buhroo AA, Hussain B, et al. (2012) Mechanisms of plant defense against insect herbivores. Plant Signal Behav 7: 1306-1320.[crossref]

16. Kaur R, Arora S (2015) Alkaloids - Important therapeutic secondary metabolites of plant origin. J Crit Rev2: 1-8.

17. Singh B, Sharma RA (2015) Plant terpenes: defense responses, phylogenetic analysis, regulation and clinical applications. 3 Biotech5: 129-151. 
18. Kumar S, Pandey AK (2013) Chemistry and biological activities of flavonoids: an overview. ScientificWorldJournal 2013: 162750.[crossref]

19. Nathanson JA (1984) Caffeine and related methylxanthines: possible naturally occurring pesticides. Science 226: 184-187. [crossref]

20. Steppuhn A, Gase K, Krock B, Halitschke R, Baldwin IT (2004) Nicotine's defensive function in nature. PLoS Biol 2: E217.[crossref]

21. Vetter J (2000) Plant cyanogenic glycosides. Toxicon 38: 11-36.[crossref]

22. Hopkins RJ, van Dam NM, van Loon JJ (2009) Role of glucosinolates in insect-plant relationships and multitrophic interactions. Annu Rev Entomol 54: 57-83.[crossref]

23. Soderlund DM, Bloomquist JR (1989) Neurotoxic actions of pyrethroid insecticides. Annu Rev Entomol 34: 77-96.[crossref]

24. Madhuri S, Ashwini U. Hegde, Srilakshmi NS, Prashith Kekuda TR (2014) Antimicrobial activity of Citrus sinensis and Citrus aurantium peel extracts. $J$ Pharmaceut Scient Innov 3: 366-368

25. Mordue AJ, Nisbet AJ (2000) Azadirachtin from the neem tree Azadirachta indica: its action against insects. An Soc Entomol Brasil29: 615-632.

26. Katz TM, Miller JH, Hebert AA (2008) Insect repellents: historical perspectives and new developments. J Am Acad Dermatol 58: 865-871.[crossref]

27. Norn S, Kruse PR (2004) Cardiac glycosides: from ancient history through Withering's foxglove to endogeneous cardiac glycosides. Dan Medicinhist Arbog 1: 119-132.

28. Francis G, Kerem Z, Makkar HP, Becker K (2002) The biological action of saponins in animal systems: a review. Br J Nutr 88: 587-605.[crossref]

29. Koes RE, Quattrocchio F (1994) The flavonoid biosynthetic pathway in plants: function and evolution. BioEssays 16: 123-132.

30. Simmonds MS (2003) Flavonoid-insect interactions: recent advances in our knowledge. Phytochemistry 64: 21-30.[crossref]

31. Tabashnik BE (1987) Plant secondary compounds as oviposition deterrents for cabbage butterfly,Pieris rapae (Lepidoptera: Pieridae). J Chem Ecol 13: 309-316.[crossref]

32. Stapleton AE (1992) Ultraviolet Radiation and Plants: Burning Questions. Plant Cell 4: 1353-1358.[crossref]

33. Hammerschmidt R, Dann EK (1999) The role of phytoalexins in plant protection. Novartis Found Symp 223: 175-187.[crossref]

34. Tomiyama K, Sakuma T, Ishizaka N, Sato N, Katsui N, et al. (1968) A new anrifungal substance isolated from resistant potato tuber tissue infected by pathogens. Phytopathology 58: 115-116.

35. Moctezuma C, Hammerbacher A, Heil M, Gershenzon J, Méndez-Alonzo R, et al. (2014) Specific polyphenols and tannins are associated with defense against insect herbivores in the tropical oak Quercus oleoides. J Chem Ecol 40: 458-467. [crossref]

36. Mans DRA (2013) From forest to pharmacy: plant-based traditional medicines as sources for novel therapeutics. Academia J Med Plants 1: 101-110.

37. Trescot AM, Datta S, Lee M, Hansen H (2008) Opioid pharmacology. Pain Physician 11: S133-153.[crossref]

38. Betcher AM (1977) The civilizing of curare: a history of its development and introduction into anesthesiology. Anesth Analg 56: 305-319. [crossref]

39. Lee MR1 (2007) Solanaceae IV: Atropa belladonna, deadly nightshade. $J$ R Coll Physicians Edinb 37: 77-84.[crossref]

40. Breckenridge A (2006) William Withering's legacy--for the good of the patient. Clin Med (Lond) 6: 393-397.[crossref]

41. Reyburn H, Mtove G, Hendriksen I, von Seidlein L (2009) Oral quinine for the treatment of uncomplicated malaria. BMJ 339: b2066.[crossref]

42. Bertani S, Houël E, Stien D, Chevolot L, Jullian V, et al. (2006) Simalikalactone D is responsible for the antimalarial properties of an Amazonian traditional remedy made with Quassia amara L. (Simaroubaceae). J Ethnopharmacol 108: 155-157.[crossref]

43. van Der Heijden R, Jacobs DI, Snoeijer W, Hallard D, Verpoorte R (2004) The Catharanthus alkaloids: pharmacognosy and biotechnology. Curr Med Chem 11: 607628. [crossref]

44. Hadden DR (2005) Goat's rue - French lilac - Italian fitch - Spanish sainfoin: gallega officinalis and metformin: the Edinburgh connection. $J R$ Coll Physicians Edinb 35: 258-260. [crossref]

45. Cragg GM, Newman DJ, Weiss RB (1997) Coral reefs, forests, and thermal vents: the worldwide exploration of nature for novel antitumor agents. Semin Oncol 24: 156-163. [crossref]

46. Hammond DS (2005) Tropical rainforests of the Guiana Shield. CABI Publishing, Wallingford, UK.

47. Szczesniak PA (2000) The mineral industry of Suriname. In: US geological survey minerals yearbook.

48. General Bureau of Statistics (2014) Suriname in numbers 303-2014-04. Basic indicators. General Bureau of Statistics, Paramaribo (Suriname).

49. World Data Atlas (2016) Suriname - Data and statistics

50. General Bureau of Statistics/Census office (2013) Suriname in numbers 2013/05 Results of the eight general census of Suriname, Demographic and social characteristics and migration. General Bureau of Statistics, Paramaribo (Suriname).

51. Helman A (1977) Cultural mosaic of Suriname. A contribution to mutual understanding De Walburg Pers, Zutphen

52. Ministry of Health (2008) Report of the Director of Health 2005-2007. Ministry of Health Republic of Suriname, Paramaribo.

53. Pawiroredjo JC, Minderhoud J, Mans DRA, Themen HCI, Bueno de Mesquita-Voigt A-MT, et al. (2016) The cataract situation in the Republic of Suriname: an effective intervention program to increase the cataract surgical rate in a developing country. $\mathrm{Br}$ J Ophthalmol 1: 1-5.

54. Herndon CN1, Uiterloo M, Uremaru A, Plotkin MJ, Emanuels-Smith G, et al. (2009) Disease concepts and treatment by tribal healers of an Amazonian forest culture. $J$ Ethnobiol Ethnomed 5: 27. [crossref]

55. Joseph B, Jini D (2013) Antidiabetic effects of Momordica charantia (bitter melon) and its medicinal potency. Asian Pac J Trop Dis3: 93-102.

56. Onwuanibe RC (1979) The philosophy of African medicinal practice. J Opin9: 25-28.

57. Wooding CJ (1979) Traditional healing and medicine in Winti: a sociological interpretation. J Opin 9: 35-40.

58. Van Andel TR, Ruysschaert S (2011) Medicinal and ritual plants of Suriname. KIT Publishers, Amsterdam.

59. Matkovic Z, Zivkovic V, Korica M, Plavec D, Pecanic S, et al. (2010) Efficacy and safety of Astragalus membranaceus in the treatment of patients with seasonal allergic rhinitis. Phytother Res 24: 175-181. [crossref]

60. Harley CB, Liu W, Blasco M, Vera E, Andrews WH, et al. (2011) A natural product telomerase activator as part of a health maintenance program. Rejuvenation Res 14 45-56. [crossref]

61. Kumar VS, Navaratnam V (2013) Neem (Azadirachta indica): prehistory to contemporary medicinal uses to humankind. Asian Pac J Trop Biomed 3: 505-514. [crossref]

62. Alzohairy MA (2016) Therapeutics Role of Azadirachta indica (Neem) and Their Active Constituents in Diseases Prevention and Treatment. Evid Based Complement Alternat Med 2016: 7382506.[crossref]

63. Tjong Ayong G (1989) The use of medicinal plants by the Javanese in Suriname. Instituut voor de Opleiding van Leraren, Paramaribo, Suriname

64. The Nagoya Protocol (2016) Access and Benefit-sharing.

65. The Convention on Biological Diversity (2016)

66. IUCN (2015) The IUCN Red List of threatened species, Version 4.

67. Stephen HJM (1979) Herbal medicines from Suriname: their applications in folk medicine and wizardry. De Driehoek, Amsterdam.

68. May AF (1982) Surinamese folk medicine. A collection of Surinamese medicinal herbs. De Walburg Pers,

69. Titjari (1985) Encyclopedia of plant-based forms of treatment. Folk medicines from sunny Suriname). Sangrafoe, Amsterdam, The Netherlands.

70. Heyde H (1987) Surinamese medicinal plants, 2nd ed. Westfort, Paramaribo (Suriname).

71. Slagveer JL (1990) Surinamese herbal medicines. De West; Paramaribo (Suriname).

72. Sedoc NO (1992) Afro-Surinamese natural remedies: over two hundred commonly used medicinal herbs. Vaco Press, Paramaribo (Suriname).

73. Veth B (1990) Useful and medicinal plants of the Wayana Indians in French Guiana 
and Suriname. Nationaal Herbarium Nederland, Universiteit Utrecht, Utrecht.

74. Raghoenandan UPD (1994) An ethnobotanical investigation among Hindustanis in Suriname. Anton de Kom Universiteit van Suriname, Paramaribo.

75. Haripersaud PP (2009) Collecting biodiversity. Universiteit Utrecht, Utrecht

76. De Filipps RA, Maina SL, Crepin J (2004) Medicinal plants of the Guianas, Department of Botany, National Museum of Natural History, Smithsonian Museum, Washington DC.

77. Dragtenstein F (2004) Loyalty to Whites. Quassie van Nieuw Timotibo, strife and struggle in the 18th century in Suriname. NiNsee/KIT Publishers, Amsterdam

78. Premgamone A, Sriboonlue P, Disatapornjaroen W, Maskasem S, Sinsupan N, et al. (2001) A long-term study on the efficacy of a herbal plant, Orthosiphon grandiflorus, and sodium potassium citrate in renal calculi treatment. Southeast Asian J Trop Med Public Health 32: 654-660.

79. Mans DR, Beerens T, Magali I, Soekhoe RC, Schoone GJ, et al. (2016) In vitro evaluation of traditionally used Surinamese medicinal plants for their potential antileishmanial efficacy. J Ethnopharmacol 180: 70-77.[crossref]

80. Ramdas S (2015) Perceptions and treatment of cutaneous leishmaniasis in Suriname: a medical-anthropological perspective (thesis). University of Amsterdam, Amsterdam

81. Rasoanaivo P, Wright CW, Willcox ML, Gilbert B (2011) Whole plant extracts versus single compounds for the treatment of malaria: synergy and positive interactions. Malar J 10 Supp 11: S4.[crossref]

82. Bipat R, Toelsie JR, Joemmanbaks RF, Gummels JM, Klaverweide J, et al. (2008) Effects of plants popularly used against hypertension on norepinephrine-stimulated guinea pig atria. Pharmacogn Mag 13: 12-19.

83. Mans DRA, Toelsie JR, Jagernath Z, Ramjiawan K, van Brussel A, et al. (2004) Assessment of eight Surinamese plant-derived preparations for their spasmolytic potential using the isolated guinea pig ileum. Pharm Biol 42: 422-429.

84. Mans DRA, Toelsie JR, Oedairadjsingh K, Magali I, Soekhoe R, et al. (2014) Evaluation of Surinamese medicinal plants for their potential bronchospasmolytic effects in isolated guinea pig tracheal chains. Res J Med Plant.

85. Mikus J, Steverding D (2000) A simple colorimetric method to screen drug cytotoxicity against Leishmania using the dye Alamar Blue. Parasitol Int 48: 265-269.[crossref]

86. Van den Bogaart E, Schoone GJ, England P, Faber D, Orrling KM, et al. (2014) Simple colorimetric trypanothione reductase-based assay for high-throughput screening of drugs against Leishmania intracellular amastigotes. Antimicrob Agents Chemother58: 527-535.
87. Van der Meide WF, Guerra J, Schoone GJ, Farenhorst M, Coelho L, et al. (2008) Comparison between quantitative nucleic acid sequence-based amplification, realtime reverse transcriptase PCR and real-time PCR for quantification of Leishmania parasites. J Clin Microbiol 46: 73-78.

88. van der Meide WF, Jensema AJ, Akrum RA, Sabajo LO, Lai A Fat RF, et al. (2008) Epidemiology of cutaneous leishmaniasis in Suriname: a study performed in 2006. Am J Trop Med Hyg 79: 192-197.[crossref]

89. Hu RVPF, Straetemans M, Kent AD, Sabajo LOA, de Vries HJC, et al. (2015) Randomized single-blinded non-inferiority trial of $7 \mathrm{mg} / \mathrm{kg}$ penthamidine isethionate versus $4 \mathrm{mg} / \mathrm{kg}$ pentamidine isethionate for cutaneous leishmaniasis in Suriname. PLoS Negl Trop Dis 9: e0003592.

90. Carmeliet P (2005) Angiogenesis in life, disease and medicine. Nature 438: 932-936. [crossref]

91. Egginton S (2010) Angiogenesis - may the force be with you! J Physiol 588: 4615 4616. [crossref]

92. Mans DRA (20150 Blood, sweat, and tears. Angiogenesis, angiogenesis-dependent diseases, and angiogenesis-interfering therapies. Int Arch Med 01/2015; 8 (131).

93. Folkman J (1971) Tumor angiogenesis: therapeutic implications. $N$ Engl J Med 285 1182-1186.[crossref]

94. Vichai V, Kirtikara K (2006) Sulforhodamine B colorimetric assay for cytotoxicity screening. Nat Protoc 1: 1112-1116.[crossref]

95. Chen HC (2005) Boyden chamber assay. Methods Mol Biol 294: 15-22.[crossref]

96. Liang CC, Park AY, Guan JL (2007) In vitro scratch assay: a convenient and inexpensive method for analysis of cell migration in vitro. Nat Protoc 2: 329-333.[crossref]

97. Arnaoutova I, George J, Kleinman HK, Benton G (2009) The endothelial cell tube formation assay on basement membrane turns 20: state of the science and the art. Angiogenesis 12: 267-274.[crossref]

98. Serbedzija GN, Flynn E, Willett CE (1999) Zebrafish angiogenesis: a new model for drug screening. Angiogenesis 3: 353-359.[crossref]

99. Poss KD, Keating MT, Nechiporuk A (2003) Tales of regeneration in zebrafish. Dev Dyn 226: 202-210.[crossref]

100. Mans DRA, Toelsie JR, Djotaroeno M, Friperson P, Pawirodihardjo J, et al. (2015) Anti-angiogenic rather than pro-angiogenic and wound healing-promoting effects of Lantana camara L. (Verbenaceae) in a zebra fish model of tissue regeneration and in cultured human umbilical vein endothelial cells. Eur J Med Plants 9: 1-12. 